\title{
Subjective Sleep Quality among Patients with Irritable Bowel Syndrome Attending Outpatient Clinic in Zagazig University Hospital
}

\author{
${ }^{1}$ Amany M. AbdAllah, ${ }^{2}$ Mahmoud A. Sharafeddin. \\ ${ }^{1}$ Family Medicine department, ${ }^{2}$ Internal Medicine department, faculty of Medicine, Zagazig \\ University, Egypt
}

\begin{abstract}
Objectives: to assess sleep quality among patients with Irritable bowel syndrome (IBS) and to determine its association with disease severity. Method: a cross-sectional study was applied on 275 patients with IBS attending Internal Medicine outpatient clinic, Zagazig University hospital. Diagnosis was established using ROME IV criteria. Patients underwent history taking and clinical examination. The Sleep quality was measured using the Pittsburgh Sleep Quality Index (PSQI). Fatigue severity scale (FSS) and IBS severity and IBS- severity scoring system (IBS-SSS) were utilized to measure fatigue and disease severity among patients respectively. Results: Mean age of patients was 32.43 years. Male represents $59.6 \%$ and $47.3 \%$ had middle socioeconomic class (SES). About one third had IBS-diarrhea predominant, and $46.9 \%$ had mild form. FSS score fluctuated between 9 to 63 with mean 37.29. Poor sleep quality was present in $52.7 \%$. There was significant relation between sleep quality and marital status, FSS score and IBS severity. There was significant positive correlation between PSQI global score and both FSS and IBS-SSS. Being married, having mild, moderate IBS, and low SES significantly increased risk of poor sleep quality by 12.97 , 4.71, 2.79, 26.25, folds respectively while lower FSS was a significant protective factor. Conclusion: Poor sleep quality was prevalent among patient with IBS. Being married, mild, moderate IBS, and low SES were significant risk factors. Patients should be screened for poor sleep quality with rapid method as PSQI and patients with abnormal scores should do further investigations.
\end{abstract}

Keywords: Sleep, severity, Fatigue, irritable, syndrome

Corresponding author: Amany M. AbdAllah. E-mail:dr.amanymohammed@gmail.com

\section{Introduction}

Irritable bowel syndrome (IBS) is the most prevalent functional gastrointestinal disorder (FGID), affecting approximately $14 \%$ of the population with female preponderance. ${ }^{1}$ IBS is a chronic disorder, which significantly raised health care expenditures and led to a drop in patients' quality of life. $^{2-3}$

The diagnosis can be established on the basis of Rome IV criteria hand in hand with a complete history, physical examination, and some diagnostic tests. ${ }^{4}$
Rome IV demarcated IBS as a functional bowel disorder in which recurrent abdominal pain is associated with defecation or alteration in bowel habits for at least 6 months and should be present through the preceding 3 months. ${ }^{5}$

Changes in the gut microbiome, ${ }^{6}$ troubles in gastrointestinal motility, alterations in the enteric nervous system, synchronized psychological distress, and visceral hypersensitivity are probably incriminated in pathogenesis of $\mathrm{IBS}^{2-4}$ These altered 
pathophysiologic processes lead to discrepancies in symptom expression, making IBS a heterogeneous disorder.

Sleep ailments had detrimental consequence on overall health. Sleep disorders led to numerous adverse effects. ${ }^{7}$

Sleep disturbances in IBS patients may lead to hypersensitivity to visceral and somatic pain that can result via changes in central nervous system responses to peripheral pain signals within brain regions known to modulate the affective and cognitive responses to pain, such as the homeostatic afferent processing network ${ }^{(8)}$.This study was done to assess sleep quality among patients with Irritable bowel syndrome (IBS) and to correlate its association with disease severity.

Research question: Does IBS affect sleep quality? Can impaired sleep quality increase disease severity or deteriorate general condition of patients?

\section{Methods}

A cross sectional study was held through the period from January to August 2019 at Internal Medicine outpatient clinic in Zagazig University hospitals.

Assuming that prevalence rate of sleep disorders in IBS in Middle East region was $35.4 \%$ and attendance rate of patients with IBS attending Internal Medicine outpatient clinic was 1250 patients/6 months, so, the sample was calculated using EPI open to be 275 patients at power of study $80 \%$ and confidence level $95 \%$.

Inclusion criteria: Adult patients of both sexes. Exclusion criteria:Concomitant comorbidities, Structural GI disorders as (inflammatory bowel diseases), Any other disease or drugs known to affect sleep quality

A systematic random sampling technique was adopted for selection of cases. As the total number of patients attending outpatient clinic was 1250 and sample size was 275 so the sampling interval was 4.5.
Hence, each $4^{\text {th }}$ patient meeting inclusion criteria was selected.

\section{Study tools}

Socio-economic level was evaluated using the questionnaire by El Gilany et al., ${ }^{10}$ Socio-demographic score $<50 \%$ (low), score $50 \%-<75 \%$ (middle) and score $\geq 75 \%$ (high) after modification.

Pittsburgh Sleep Quality Index (PSQI): Sleep quality over one month was evaluated by PSQI. It involves 19 questions. It includes seven component subscales: subjective sleep quality, sleep latency, sleep duration, habitual sleep efficiency, sleep disturbances, use of sleep medications, and daytime dysfunction. Total score ranges from 0 to 21 with higher ones denoting poorer sleep quality. Sleep disorders can be established if overall score is greater than $8^{(11)}$. Arabic translation of Suleiman et al. ${ }^{(12)}$ was used with Cronbach's $\alpha$ for the PSQI Arabic form was 0.74. Fatigue severity scale (FSS): A self-reported questionnaire consists of 9 statements rating severity of fatigue symptoms in the previous one week regarding how it affects motivation, physical function, and daily living activities. ${ }^{13}$ Total score ranged from 9 to 63 with higher scores reflects higher severity. ${ }^{14}$ Arabic form of Al-Sobayel et al. ${ }^{15}$ was used. Test-retest reliability and internal consistency of the FSS-Ar was adequate (Cronbach's $\alpha=0.84){ }^{15}$

Irritable bowel syndrome- severity scoring system (IBS-SSS): The IBS-SSS is a 5question assessment to appraise the severity, frequency of abdominal pain, intensity of abdominal distention, frustration with bowel habits, and intrusion in quality of life 10 days ago. It is a 100point visual analogue scale. ${ }^{15}$ Scores ranges from 0 to 500 with higher scores indicating more severe symptoms. Based on total score, patients are categorized as having mild (75-175), moderate (175-300), 
or severe (>300) IBS. $^{15}$ The Arabic translation

Table (1) Sociodemographic and clinical characteristics of the studied patients with IBS:

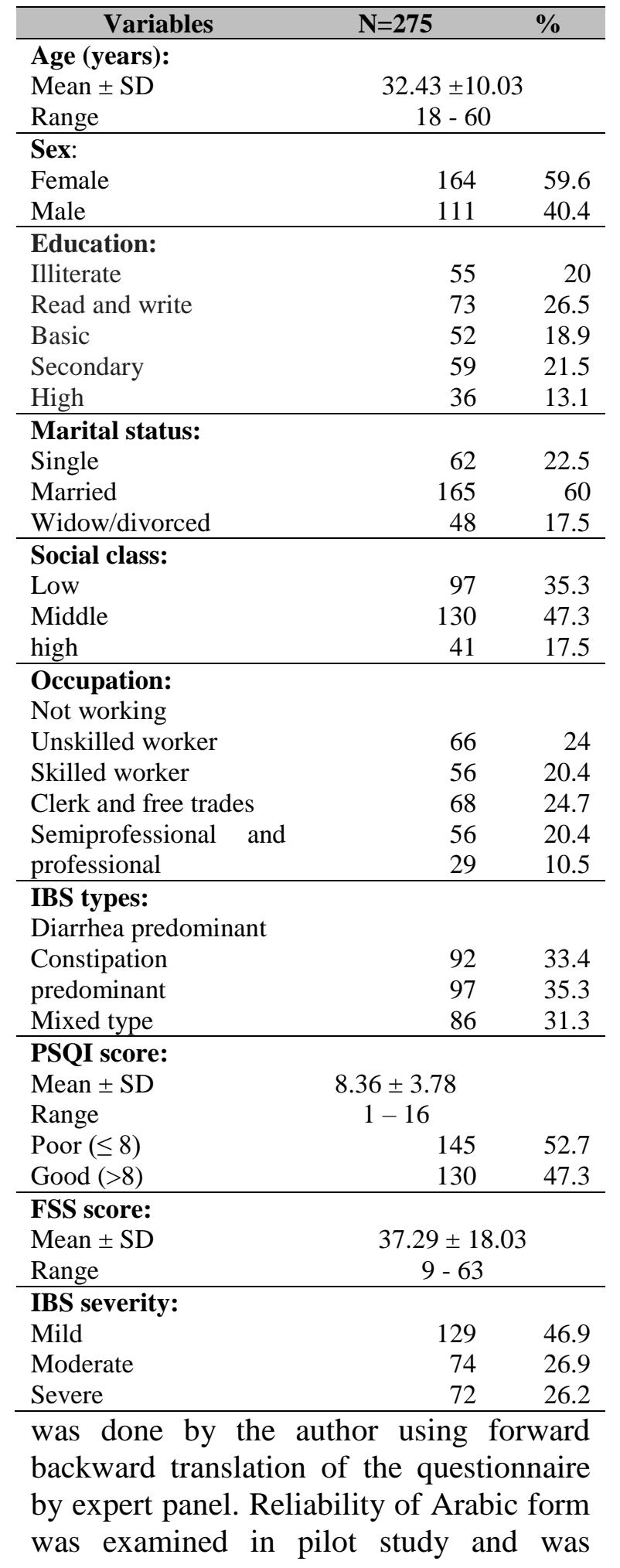

adequate (Cronbach's $\alpha=0.90$ ). A pilot study was accomplished on $10 \%$ of the sample size to check study feasibility, clarity of the questionnaires and calculate the time essential to fill in each questionnaire. Study tools were sufficiently clear and no adjustment was needed.

After obtaining patients' consent, each patient underwent details history taking and thorough clinical examination. The patients filled in the questionnaires with the aid of researcher. Required time for each patient fluctuated from 45 to 50 minutes.

\section{Administrative and Ethical approval}

An official authorization was gotten from Ethical committee of Faculty of Medicine, Zagazig University. The required official approvals to accomplish the research were gotten from the head of the Internal Medicine department at Zagazig University Hospitals. An informed consent was obtained from all participants. Strict confidentiality was reassured.

\section{Statistical analysis}

Data analysis was accomplished using the software SPSS (Statistical Package for the Social Sciences) version 20. Quantitative data was represented using means and standard deviations. Categorical variables were designated using their absolute frequencies and were associated using Chi square test. Kolmogorov-Smirnov (distribution-type) and Levene (homogeneity of variances) tests were utilized to prove suppositions for use in parametric tests. For quantitative variables, independent samples t-test ( $t$ ) was used to compare means of two groups while Mann Whitney U test was used for non-normally distributed data. For categorical variables, Chi square $\left(\chi^{2}\right)$ and Fisher's exact tests were used to compare the studied groups. Spearman rank correlation coefficient was used to measure correlation between PSQI, FSS and IBS-SSS. Logistic regression 
analysis was done to evaluate risk factors for poor sleep quality. P value $<0.05$ was Table (2) Relation between sleep quality and characteristics of patients with IBS:

\begin{tabular}{|c|c|c|c|c|c|c|}
\hline \multirow[b]{2}{*}{$\begin{array}{c}\text { Patient } \\
\text { characteristics }\end{array}$} & \multirow[b]{2}{*}{$\begin{array}{c}\text { Total } \\
\mathrm{N}=275(\%)\end{array}$} & \multicolumn{2}{|c|}{ Sleep quality } & \multirow[b]{2}{*}{ p } & \multirow[b]{2}{*}{$\begin{array}{l}\text { Crude odds ratio } \\
\text { (95\% confidence } \\
\text { interval) }\end{array}$} & \multirow[b]{2}{*}{$P$ for $O R$} \\
\hline & & $\begin{array}{c}\text { Poor } \\
\mathrm{N}=145 \\
(\%) \\
\end{array}$ & $\begin{array}{c}\text { Good } \\
\mathrm{N}=130(\%)\end{array}$ & & & \\
\hline $\begin{array}{l}\text { Age groups: } \\
\leq 32 \text { years } \\
>32 \text { years }\end{array}$ & $\begin{array}{l}147(53.5) \\
128(46.5) \\
\end{array}$ & $\begin{array}{l}83(56.5) \\
62(48.4) \\
\end{array}$ & $\begin{array}{l}64(43.5) \\
66(51.6) \\
\end{array}$ & $0.184^{\S}$ & $1.38(0.86-2.22)$ & 0.184 \\
\hline $\begin{array}{l}\text { Sex: } \\
\text { Female } \\
\text { Male }\end{array}$ & $\begin{array}{r}164(59.6) \\
111(40.4) \\
\end{array}$ & $\begin{array}{l}89(54.3) \\
56(50.5) \\
\end{array}$ & $\begin{array}{l}75(45.7) \\
55(49.5) \\
\end{array}$ & $0.534^{\S}$ & $1.17(0.72-1.89)$ & 0.534 \\
\hline $\begin{array}{l}\text { Education: } \\
\text { Illiterate } \\
\text { Read and write } \\
\text { Basic } \\
\text { Secondary } \\
\text { High }\end{array}$ & $\begin{array}{r}55(20) \\
73(26.5) \\
52(18.9) \\
59(21.5) \\
36(13.1) \\
\end{array}$ & $\begin{array}{l}32(58.2) \\
35(47.9) \\
27(51.9) \\
36(61.0) \\
15(41.7)\end{array}$ & $\begin{array}{l}23(41.8) \\
38(52.1) \\
25(48.1) \\
23(39.0) \\
21(58.3)\end{array}$ & $0.613^{¥}$ & $\begin{array}{c}1.95(0.83-4.57) \\
1.29(0.58-2.89) \\
1.51(0.64-3.61) \\
2.19(0.49-2.27) \\
1 \\
\end{array}$ & $\begin{array}{l}0.123 \\
0.536 \\
0.344 \\
0.067\end{array}$ \\
\hline $\begin{array}{l}\text { Marital status: } \\
\text { Single } \\
\text { Married } \\
\text { Widow/divorced }\end{array}$ & $\begin{array}{r}62(22.5) \\
165(60) \\
48(17.5) \\
\end{array}$ & $\begin{array}{r}32(51.6) \\
101(61.2) \\
12(25.0) \\
\end{array}$ & $\begin{array}{l}30(48.4) \\
64(39.8) \\
36(75.0) \\
\end{array}$ & $0.016^{* ¥}$ & $\begin{array}{c}3.2(1.41-7.28) \\
4.73(2.29-9.77) \\
1 \\
\end{array}$ & $\begin{array}{c}0.005^{*} \\
<0.001 * * \\
\end{array}$ \\
\hline $\begin{array}{l}\text { Occupation: } \\
\text { Not working } \\
\text { Unskilled worker } \\
\text { Skilled worker } \\
\text { Clerk and free } \\
\text { trades } \\
\text { Semiprofessional } \\
\text { and professional }\end{array}$ & $\begin{array}{l}66(24.0) \\
56(20.4) \\
68(24.7) \\
56(20.4) \\
29(10.5)\end{array}$ & $\begin{array}{l}39(59.1) \\
32(57.1) \\
28(41.2) \\
34(60.7) \\
12(41.4)\end{array}$ & $\begin{array}{l}27(40.9) \\
24(42.9) \\
40(58.8) \\
22(39.3) \\
17(58.6)\end{array}$ & $0.232^{¥}$ & $\begin{array}{c}2.05(0.88-5.46) \\
1.89(0.76-4.69) \\
0.99(0.41-2.4) \\
2.19(0.88-5.46) \\
1\end{array}$ & $\begin{array}{c}0.111 \\
0.168 \\
0.985 \\
0.0898\end{array}$ \\
\hline $\begin{array}{l}\text { Social class: } \\
\text { Low } \\
\text { Middle } \\
\text { High } \\
\end{array}$ & $\begin{array}{r}93(33.8) \\
129(46.9) \\
53(19.3) \\
\end{array}$ & $\begin{array}{l}82(88.2) \\
40(31.0) \\
23(43.4) \\
\end{array}$ & $\begin{array}{l}11(11.8) \\
89(69.0) \\
30(56.6) \\
\end{array}$ & $<0.001 * *^{*}$ & $\begin{array}{c}9.72(4.2-22.3) * \\
0.59(0.3-1.13) \\
1 \\
\end{array}$ & $\begin{array}{c}<0.001 * * \\
0.11 \\
\end{array}$ \\
\hline $\begin{array}{l}\text { IBS types: } \\
\text { IBS-diarrhea } \\
\text { predominant } \\
\text { IBS-constipation } \\
\text { predominant } \\
\text { Mixed type }\end{array}$ & $\begin{array}{r}113(41.1) \\
39(14.2)\end{array}$ & $\begin{array}{r}69(56.1) \\
60(53.1) \\
16(41)\end{array}$ & $\begin{array}{r}53(46.9) \\
23(59)\end{array}$ & $0.136^{\ddagger}$ & $\begin{array}{c}1.84(0.88-3.81) \\
1.63(0.78-3.45) \\
1\end{array}$ & $\begin{array}{l}0.101 \\
0.194\end{array}$ \\
\hline $\begin{array}{l}\text { IBS severity: } \\
\text { Mild } \\
\text { Moderate } \\
\text { Severe } \\
\end{array}$ & $\begin{array}{r}129(46.9) \\
74(26.9) \\
72(26.2) \\
\end{array}$ & $\begin{array}{l}86(66.7) \\
39(52.7) \\
20(27.8) \\
\end{array}$ & $\begin{array}{l}43(33.3) \\
35(47.3) \\
52(72.2) \\
\end{array}$ & $<0.001 *^{*} *^{ \pm}$ & $\begin{array}{c}5.2(2.76-9.79) \\
2.9(1.46-5.81) \\
1 \\
\end{array}$ & $\begin{array}{c}<0.001 * * \\
0.002 *\end{array}$ \\
\hline $\begin{array}{ll}\text { Fatigue } & \text { severity } \\
\text { score: } & \\
\text { Mean } \pm \text { SD } & \end{array}$ & $\begin{array}{l}37.29 \\
18.03\end{array}$ & $29.06 \pm 15.69$ & $46.47 \pm 15.9$ & $<0.001 * * \diamond$ & & \\
\hline
\end{tabular}

considered statistically significant, $\mathrm{p} \leq 0.001$ was considered as highly significant.

\section{Results}

Age of the studied patients ranged from 18 to 60 years with mean 32.43 years. About 
$54 \%$ of them aged $\leq 35$ years old. Female constituted $59.6 \%$ of the studied patients and $60 \%$ of them were married. Concerning level of education; one fifth of them were

Table (3) Correlation between PSQI global score, IBS-SSS and FSS among the studied patients:

\begin{tabular}{|c|c|c|c|c|}
\hline \multirow[t]{2}{*}{ Variables } & \multicolumn{2}{|c|}{$\begin{array}{l}\text { PSQI global } \\
\text { score }\end{array}$} & \multicolumn{2}{|c|}{$\begin{array}{c}\text { IBS-Severity } \\
\text { Scoring System } \\
\text { (IBS-SSS) } \\
\end{array}$} \\
\hline & $\mathbf{r}$ & p & $\mathbf{r}$ & p \\
\hline $\begin{array}{l}\text { IBS-Severity } \\
\text { Scoring } \\
\text { System (IBS- } \\
\text { SSS) } \\
\end{array}$ & 0.471 & $<0.001 * *$ & & \\
\hline $\begin{array}{l}\text { Fatigue } \\
\text { severity scale } \\
\text { (FSS) }\end{array}$ & 0.649 & $<0.001 * *$ & 0.264 & $<0.001 * *$ \\
\hline
\end{tabular}

illiterate, $18.9 \%, 23.1 \%$ and $13.1 \%$ of them had basic, secondary and high education correspondingly. About one quarter of them was not working and about one third had low SES).

Regarding IBS types, about one third had IBS-diarrhea predominant and $35.3 \%$ had constipation predominant type. On assessing IBS severity, it was found that 46.9\% had mild disease and $26.2 \%$ had reported severe symptoms. Fatigue severity scale of the patients ranged from 9 to 63 with mean 37.29. (Table 1)

On measuring sleep quality using PSQI, score ranged from 1 to 16 with mean 8.36 and $52.7 \%$ of patients had poor sleep quality (Table 1).

There is statistically non-significant relation between sleep quality and each of age groups, sex, education, occupation or IBS type. Patients aged 32 years old or less had 1.38 folds increase in risk of poor sleep quality. Female non-significantly increased risk of poor quality by 1.17 folds. Patients with secondary education increased risk by 1.53 folds. Not working, unskilled worker, and clerk nonsignificantly had increased risk for poor sleep quality by $2.05,1.89$ and 2.19 folds respectively. IBS diarrhea predominant and constipation predominant nonsignificantly increased risk of poor quality by 1.84 and 1.63 folds respectively.

On the other hand, there is significant relation between sleep quality and marital status $(61.2 \%$ of married patients had poor quality; OR=2.36), SES ( $88.2 \%$ of patients with low social class had significantly augmented risk of poor sleep quality; $\mathrm{OR}=9.72$ ), IBS severity (two thirds of patients with mild disease had poor quality with increased risk by 5.2 while having moderate disease was associated with 2.9 folds increase in that risk) and fatigue severity scale (higher FSS score in patients with poor quality) (Table 2)

There is significant positive correlation between global PSQI score and both FSS score and IBS-SSS ( $r=0.649, \mathrm{p}<0.001$ and $\mathrm{r}=0.471, \mathrm{p}<0.001)$ respectively. Similarly, there is significant positive correlation between IBS-SSS and FSS scores $(\mathrm{r}=0.264, \mathrm{p}<0.001)$ (Table 3).

On doing multivariate regression analysis, decreasing FSS score (OR=0.931, $\mathrm{p}<0.001)$ was a significant protective factor against poor sleep quality. Being married $(\mathrm{OR}=5.175, \quad \mathrm{p}<0.001), \quad$ single $(\mathrm{OR}=1.283, \mathrm{p}=0.666)$, having mild IBS $(\mathrm{OR}=4.71, \mathrm{p}<0.001)$, moderate disease $(\mathrm{OR}=2.787, \quad \mathrm{p}=0.037), \quad$ low $\quad \mathrm{SES}$ $(\mathrm{OR}=26.248, \mathrm{p}<0.001)$ were significant risk factors of poor sleep quality (Table 4)

\section{Discussion}

To our knowledge, it is the first study done in Egypt to assess sleep quality in patients with IBS. The current study displayed that more than half of patients $(52.7 \%)$ with IBS had poor sleep quality which badly affected patients' lives. This problem had drawn attention of many researchers. In a meta-analysis done by Wang and 
coworkers in 2018, pervasiveness of sleep

North,

South disorders among patients within Asia,

Table (4) Logistic regression analysis of risk factors for poor sleep quality in patients with IBS:

\begin{tabular}{|c|c|c|c|c|c|}
\hline \multirow[b]{2}{*}{ Risk factors } & \multirow[b]{2}{*}{$\boldsymbol{\beta}$} & \multirow{2}{*}{$\begin{array}{c}\text { Odds } \\
\text { ratio } \\
\text { (adjusted) }\end{array}$} & \multicolumn{2}{|c|}{$95 \%$ confidence interval } & \multirow[b]{2}{*}{ p } \\
\hline & & & Lower & Upper & \\
\hline FSS (decreasing score) & -0.071 & 0.931 & 0.909 & 0.955 & $<0.001 * *$ \\
\hline Severe IBS ${ }^{\diamond}$ & & & & & $0.003 *$ \\
\hline Mild IBS & 1.55 & 4.71 & 1.934 & 11.474 & $0.001 * *$ \\
\hline Moderate IBS & 1.025 & 2.787 & 1.066 & 7.283 & $0.037 *$ \\
\hline High Social class ${ }^{\diamond}$ & & & & & $<0.001 * *$ \\
\hline Low social class & 3.268 & 26.248 & 8.201 & 84.009 & $<0.001 * *$ \\
\hline Middle social class & -0.028 & 0.73 & 0.421 & 2.246 & 0.949 \\
\hline Divorced/Widowed $^{\diamond}$ & & & & & $<0.001 * *$ \\
\hline Single & 0.249 & 1.283 & 0.414 & 3.976 & 0.666 \\
\hline Married & 2.563 & 12.97 & 4.316 & 38.975 & $<0.001 * *$ \\
\hline
\end{tabular}

America and Europe was $36.9 \%, 37.3 \%$ and $67.1 \%$ and $35.9 \%$ respectively. ${ }^{9}$

Higher prevalence was detected in another prospective; one-month study applied on 23 adult patients with IBS as $74 \%$ were found to be "poor sleepers". ${ }^{17}$ A Turkish case control study conveyed that $36 \%$ in IBS patients versus $18 \%$ of healthy volunteers had poor sleep. ${ }^{18}$ In a previous Iranian study, $61.8 \%$ IBS patients were poor sleepers. According to them, there was no significant correlation between PSQI and either sex, type or severity of IBS. $^{19}$

The current study showed that married patients had significantly poorer sleep quality. They have five folds increase in risk of having poor sleep quality. Such finding can be justified by that emotional, financial, and social problems married persons faced could augment IBS symptoms or directly affect sleep quality. Cost of drug, repeated physicians visits and dietary limitation could add constraint to family welfare which impair psychological state of patients hence increase IBS symptoms 'patients run in a vicious circle'.

The exact clarification for association between sleep disorders and IBS remains blurred. The gut-brain axis had a noteworthy contribution in pathogenesis of IBS. Central nervous system (CNS), autonomic nervous system (ANS), enteric nervous system (ENS), and hypothalamic pituitary adrenal (HPA) axis are thought to be tangled. $^{20}$ Sleep deprivation headed alteration in the ANS activity; hence sleep disorder is potentially connected to autonomic dysregulation. ${ }^{21-22}$ Sleep suppresses the HPA axis. Sleep disorder may end in a 24 hour augmented secretion of ACTH and cortisol. ${ }^{23}$ Furthermore, IBS symptoms possibly activate sympathetic nervous system and lessen sleep competency. ${ }^{24}$

Changed microbiota had a serious role in the evolution of IBS and potentially on sleep quality. Gut microbes may disturb sleep rank via degradation products as muramyl peptides (MPs), lipopolysaccharide $(\text { LPS })^{25}$ and melatonin. ${ }^{26}$ Such ingredients could trigger immune cells with release of cytokines, which might interrupt sleep. Short chain fat acids in addition to such metabolites have a detrimental effect on both central and hepatic circadian regularity. ${ }^{27}$

These mechanisms can enlighten significant link between disease severity 
and sleep quality observed in the existing study. According to the studied patients, mild and moderate disease increased risk of poor sleep by about 4.71 and 2.79 folds respectively. That also can be justified by that sleep quality and IBS severity were assessed by self-reported questionnaire with absence of objective evaluation. So it is all about what patients feel and report but without confirmation of such findings using polysomnography or objective weighing of IBS severity.

Bellini et al. ${ }^{28}$ denoted that there was nonsignificant correlation between PSQI and IBS-SSS scores. Though former studies stated that sleep disorders were associated to disease severity. ${ }^{29-30}$

Sleep disorders among female IBS patients was non-significantly higher than male patients. Increasing risk of sleep disorder and IBS in females has been stated $(43.6 \%$ versus $34.4 \%$ ) in previous study. ${ }^{9}$ Discrepancy in sex hormones, changed sensitivity to visceral and somatic pain, central handling of visceral provocations, genetics, and immunologic/microbiome may be the incriminating factors in such change. ${ }^{31}$

Another study, in disharmony with ours, stated that male IBS patients had more sleep troubles than females. ${ }^{28}$

In a prior study, there was signification association between sleep quality and both age and sex. However, no significant relation was seen between the PSQI subscales and either patient education, marital status, SES, or job. ${ }^{32}$

In the current study, low social class significantly increased risk of poor sleep quality by 26.25 folds. Low social class may augment symptoms by either decreasing compliance to treatment and diet, increasing anxiety and psychosocial stressors patients faced.
Fatigue is the third most common "extraintestinal" complaint in those with IBS, yet it is still poorly unspecified. ${ }^{33}$ Fatigue could be a root and consequence of poor sleep quality. FSS scores positively associated with PSQI scores with decreasing FSS scores was protective factors against having poor sleep quality.

Sleep disturbances appeared to be the most frequent factor that associate fatigue to IBS $^{34-36}$ Witthoft et al ${ }^{34}$ stated that fatigue was positively allied to poor sleep quality $(r=0.29, N=414)$.

Simren et $\mathrm{al}^{36}$ conveyed that IBS patients who complained of fatigue have more sleeping difficulties.

It is recommended that further prospective studies to be done using objective as well as subjective checking of sleep quality and efforts should be focused on handling sleep disorders in patients with IBS. The physician should investigate sleep quality in their patients with rapid method such as PSQI tool and patients who reported poor quality should do further investigations to confirm that finding and receive appropriate management to improve their quality of life and overall outcome.

Study limitation: This study didn't comprise control group. Objective sleep quality wasn't appraised. There was possible self-reporting bias. Being cross sectional in nature, the study delivered only association of some risk factors with bad sleep quality without confirming cause effect relation.

\section{Conclusion}

Poor subjective sleep quality was widespread among patient with IBS (52.4\%) hence it can be considered as major burden that should draw physicians' attention when handling those patients. Poor subjective sleep quality was prevalent among patient with IBS. Being married, having mild, moderate IBS, and low social 
class significantly increased risk of poor sleep quality while lower FSS was significant protective factor.

Conflict of interest: the authors declared no conflict of interest.

\section{References}

1. Lovell RM, Ford AC. Global prevalence of and risk factors for irritable bowel syndrome: a meta-analysis. Clin Gastroenterol Hepatol. 2012;10(7):712-721.e4.

2. Mearin F, Lacy BE, Chang L, et al. Bowel disorders. Gastroenterology. 2016. pii: S00165085(16)00222-5

3. Ford AC, Lacy BE, Talley NJ. Irritable bowel syndrome. $\mathrm{N}$ Engl J Med. 2017;376(26):2566-2578.

4. Ford AC, Moayyedi P, Chey WD, et al; ACG Task Force on Management of Irritable Bowel Syndrome. American College of Gastroenterology monograph on management of irritable bowel syndrome. Am J Gastroenterol. 2018;113(suppl 2):1-18

5. Lacy B.E., Mearin F., Chang L., Chey W.D., Lembo A.J., Simren M., Spiller R. Bowel

Disorders. Gastroenterology. 2016;150:1393-

1407. doi: 10.1053/j.gastro.2016.02.031.

6. Halmos EP, Christophersen CT, Bird AR, Shepherd SJ, Muir JG, Gibson PR. Consistent prebiotic effect on gut microbiota with altered FODMAP intake in patients with Crohn's disease: a randomised, controlled cross-over trial of well-defined diets. Clin Transl Gastroen. 2016;7:e164.

7. Medic G, Wille M, Hemels ME. Short- and long-term health consequences of sleep disruption. Nat Sci Sleep. 2017;9:151-161.

8. Larsson MB, Tillisch $\mathrm{K}$, Craig $\mathrm{AD}$, et al. Brain responses to visceral stimuli reflect visceral sensitivity thresholds in patients with irritable bowel syndrome. Gastroenterology. 2012;142(3):463 -472 . e3

9. Wang B, Duan R, Duan L. Prevalence of sleep disorder in irritable bowel syndrome: A systematic review with meta-analysis. Saudi J Gastroenterol. 2018;24(3):141-150.

10.El-Gilany A, El-Wehady A, and El-Wasify $M$. Updating and validation of the socioeconomic status scale for health research in Egypt. East Mediterr Health 2012 J; 18(9):962-8.

11.Buysse, D.J., Reynolds, C.F., Monk, T.H., Berman, S.R., \& Kupfer, D.J. The Pittsburgh Sleep Quality Index: A new instrument for psychiatric practice and research. Psychiatry Research. 1989; 28(2): 193-213

12.SuleimanK, Al- Hadid L., Duhni A.:Psychometric Testing of the Arabic version of the Pittsburgh Sleep Quality.Journal of Natural Sciences Research.2012; 2 (8): 15-19 13. Krupp LB, LaRocca NG, Muir-Nash J, Steinberg AD. The fatigue severity scales. Application to patients with multiple sclerosis and systemic lupus erythematosus. Arch Neurol. 1989;46:1121-1123

14. Whitehead L. The measurement of fatigue in chronic illness: a systematic review of unidimensional and multidimensional fatigue measures. J Pain Symptom Manage. 2009;37:107-128.

15.Al-Sobayel HI, Al-Hugail HA, AlSaif RM, et al. Validation of an Arabic version of Fatigue Severity Scale. Saudi Med J. 2016;37(1):73-78.

16.Francis C.Y, Morris J. \& Whorwell P.J. The irritable bowel severity scoring system: a simple method of monitoring irritable bowel syndrome and its progress. Aliment Pharmacol Ther. 1997; 11: 395-402

17.Goldsmith G1, Levin JS. Effectof sleep quality on symptoms of irritable bowel syndrome. Dig Dis Sci. 1993;38 (10):1809-14. 18. Wu J, Song Z, Xu Y, Zhang YM, Shen RH. [Probe into sleep quality in the patients with irritable bowel syndrome]. Zhonghua Nei Ke Za Zhi. 2010;49:587-90.

19.Baniasad Nadieh, Dehesh Mohammad Moein, Mohebbi Elham, Hayatbakhsk Mahdy, Oghabian Zohreh. Assessing the sleep quality and depression anxiety and stress in irritable bowel syndrome patients. Arq. Gastroenterol. 2017; 54( 2 ): 163-166.

20.Carabotti M, Scirocco A, Maselli MA, Severi C. The gut-brain axis: Interactions between enteric microbiota, central and enteric nervous systems. Ann Gastroenterol 2015;28:203-9. 
21.Miglis MG. Autonomic dysfunction in primary sleep disorders. Sleep Med 2016;19:40-9.

22.Tobaldini E, Costantino G, Solbiati M, Cogliati C, Kara T, Nobili L, et al. Sleep, sleep deprivation, autonomic nervous system and cardiovascular diseases. Neurosci Biobehav Rev 2017;74:321-9.

23. Vgontzas AN, Chrousos GP. Sleep, the hypothalamic-pituitary-adrenal axis, and cytokines: Multiple interactions and disturbances in sleep disorders. Endocrinol Metab Clin North Am 2002;31:15-36.

24. Schlereth T, Birklein F. The sympathetic nervous system and pain. Neuromolecular Med 2008; 10:141-7.

25.Krueger JM, Opp MR. Sleep and Microbes. Int Rev Neurobiol 2016;131:207-25.

26. Wong RK, Yang C, Song GH, Wong J, Ho $\mathrm{KY}$. Melatonin regulation as a possible mechanism for probiotic (VSL\#3) in irritable bowel syndrome: A randomized doubleblinded placebo study. Dig Dis Sci 2015;60:186-94.

27.Leone V, Gibbons SM, Martinez K, Hutchison AL, Huang EY, Cham CM, et al. Effects of diurnal variation of gut microbes and high-fat feeding on host circadian clock function and metabolism. Cell Host Microbe 2015; 17:681-9.

28.Bellini M, Gemignani A, Gambaccini D, et al. Evaluation of latent links between irritable bowel syndrome and sleep quality. World $\mathbf{J}$ Gastroenterol. 2011;17(46):5089-5096. doi:10.3748/wjg.v17.i46.5089

29.Patel A, Hasak S, Cassell B, et al. Effects of disturbed sleep on gastrointestinal and somatic pain symptoms in irritable bowel syndrome. Aliment Pharmacol Ther.
2016;44(3):246-258. doi:10.1111/apt.13677 and

30.Moradian-Shahrbabaki M, Vahedi H, Sadeghniiat-Haghighi K , Mansour Shamsipour. Tracing the Relationships between Sleep Disturbances and Symptoms of Irritable Bowel Syndrome J Sleep Sci, Vol. 1, No. 3, 2016.

31.Mong JA, Cusmano DM. Sex differences in sleep: Impact of biological sex and sex steroids. Philos Trans R Soc Lond B Biol Sci 2016;371:20150110.

32.Uner N, Elif Unsal Avdal, Berna Nilgun Ozgursoy Uran and Zehra Ecesoy Akpinar,. Analysis of the Effect of Sleep Quality on the Life Quality of Irritable Bowel Syndrome Patients Hepatol Gastroint Dis 2017, 3(1):2-5)

33.Han, Claire Jungyoun et al: Fatigue in Irritable Bowel Syndrome: A Systematic Review and Meta-analysis of Pooled Frequency and Severity of Fatigue. Asian Nursing Research .2016;10(1):1 - 10

34.Witthoft, M., Hiller, W., Loch, N., and Jasper, F. The latent structure of medically unexplained symptoms and its relation to functional somatic syndromes. Int J Behav Med. 2013; 20: 172-183.

35.Longstreth, G.F., Bolus, R., Naliboff, B., Chang, L., Kulich, K.R., Carlsson, J. et al. Impact of irritable bowel syndrome on patients' lives: development and psychometric documentation of a disease-specific measure for use in clinical trials. Eur J Gastroenterol Hepatol. 2005; 17: 411-420,

36.Simren, M., Svedlund, J., Posserud, I., Bjornsson, E.S., and Abrahamsson, $\mathrm{H}$. Predictors of subjective fatigue in chronic gastrointestinal disease. Aliment Pharmacol Ther. 2008; 28: 638-647. 